\title{
Thrombolytic Therapy for Stroke: Intravenous Tenecteplase Era
}

\author{
Mohammad Abdolia, Pegah Mohammadi ${ }^{\mathrm{b}}$, Ashkan Mowlac, d
}

Acute ischemic stroke (AIS) is a worldwide health burden and the leading cause of disability in adults. The management of AIS is developing rapidly. Currently, the two Food and Drug Administration (FDA)-approved treatment options for AIS are intravenous thrombolysis (IVT) with alteplase within the first $4.5 \mathrm{~h}$ of the AIS symptom onset and endovascular treatment (EVT) in patients with an occlusive clot in one of the intracranial large vessels within the first $24 \mathrm{~h}$ of symptom onset depending on the salvageability of the brain tissue [1-10]. Some studies have shown the potential benefit of EVT during the first 16 to $24 \mathrm{~h}$ from the AIS symptom onset if there is a favorable penumbra without a large infarct core [11, 12]. Another study revealed that EVT within 6 to $16 \mathrm{~h}$ after onset of AIS symptom could decrease the length hospital stay and improve patient functional outcome [13].

Alteplase is an intravenous recombinant tissue plasminogen activator (rTPA) with a short half-life that needs continuous in-

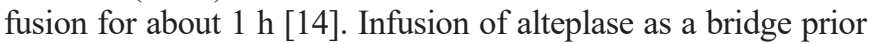
to EVT is still a treatment option for eligible AIS patients with intracranial large vessel occlusions [15-17]. Thus far, alteplase is the only FDA-approved pharmacological treatment for AIS [1, 5, 18]; however, infusion of alteplase has a relatively low rate of recanalization and reperfusion of the large vessel occlusions prior to EVT; hence, it might not be the ideal treatment option $[15,19]$.

Tenecteplase is a modified form of alteplase with 14-fold more fibrin specificity and enhanced ability for thrombolysis. It also has a longer half-life and 80 times greater resistance to plasminogen activator inhibitor-1 compared to the alteplase; as such, it can be used as an intravenous bolus rather than a bolus followed by $1 \mathrm{~h}$ infusion as with alteplase [20]. Single bolus infusion of tenecteplase can give practical benefits to AIS patients who need transportation between hospitals to access EVT [15]. Single bolus infusion of tenecteplase can also

Manuscript submitted June 8, 2020, accepted June 15, 2020

Published online June 30, 2020

aNational Skull Base Foundation, Thousand Oaks, CA 91360, USA

${ }^{\mathrm{b}}$ California Institute of Neuroscience, Thousand Oaks, CA 91360, USA

'Division of Endovascular Neurosurgery, Department of Neurological Surgery, Keck School of Medicine, University of Southern California (USC), Los Angeles, CA 90033, USA

${ }^{\mathrm{d} C}$ Corresponding Author: Ashkan Mowla, Division of Endovascular Neurosurgery, Department of Neurological Surgery, Keck School of Medicine, University of Southern California (USC), Suite 3300, 1200 North State St., Los Angeles, CA 90033, USA. Email: mowla@usc.edu reduce the time to receive EVT after the onset of stroke symptoms [16]. Furthermore, according to the information available on drugs.com, in the USA, tenecteplase would cost much less when compared with the alteplase [20].

To the best of our knowledge, at least five randomized clinical trials that compared alteplase with tenecteplase in the treatment of AIS have shown no significant differences in the mortality rate or in the chance of neurological recovery between these two options [15]. Parson et al [18], in a randomized clinical trial on AIS patients who received thrombolytic therapy, found that tenecteplase was superior to alteplase concerning the angiographic outcomes, rate of reperfusion, and also neurological improvement in $24 \mathrm{~h}$. They also showed lower rate of severe disability at 90 days [18].

Campbell et al [15] studied tenecteplase $0.25 \mathrm{mg} / \mathrm{kg}$ versus the standard dose of alteplase for patients with AIS within $4.5 \mathrm{~h}$ of symptom onset prior to EVT. They reported significantly greater chance of reperfusion of the occluded vessel along with meaningfully better chance of 3 -month functional outcome $[15,20]$.

Concerning the safety outcomes, two of the most recent meta-analyses comparing the efficacy and safety of the both treatment options for AIS, found no statistically significant difference in the rates of intracerebral hemorrhage between the two, but there were tendency toward lower rate of intracerebral hemorrhage with tenecteplase (odds ratio (OR): $0.81,95 \%$ confidence interval (CI): $0.56-1.17 ; \mathrm{P}=0.26)[14,21]$.

When it comes to the administration of the tenecteplase, current evidences advocate that $0.25 \mathrm{mg} / \mathrm{kg}$ (maximum $25 \mathrm{mg}$ ) is the most appropriate dose. The $0.1 \mathrm{mg} / \mathrm{kg}$ dose was not as effective as $0.25 \mathrm{mg} / \mathrm{kg}$ dose in the study by Parsons et al [18], and the $0.4 \mathrm{mg} / \mathrm{kg}$ dose may result in higher rates of intracerebral hemorrhage as shown by Haley et al [22].

In conclusion, tenecteplase is shown to be as effective as alteplase with respect to functional outcome after treatment of AIS. Furthermore, it can be used as an intravenous bolus rather than a bolus followed by $1 \mathrm{~h}$ infusion as with alteplase which makes it more convenient to administer and may have lower bleeding risks when compared to alteplase. It is also cheaper. Health care providers should contemplate using tenecteplase rather than alteplase for the treatment of AIS at the recommended dose if available in their centers.

\section{Acknowledgments}

None to declare. 


\section{Financial Disclosure}

None to declare.

\section{Conflict of Interest}

None to declare.

\section{Author Contributions}

All authors have contributed to the theoretical formalism, designing the study, data collection, data analysis and writing the manuscript.

\section{Data Availability}

The authors declare that data supporting the findings of this study are available within the article.

\section{References}

1. Mowla A, Doyle J, Lail NS, Rajabzadeh-Oghaz H, Deline C, Shirani P, Ching M, et al. Delays in door-to-needle time for acute ischemic stroke in the emergency department: A comprehensive stroke center experience. J Neurol Sci. 2017;376:102-105.

2. Mowla A, Singh K, Mehla S, Ahmed MK, Shirani P, Kamal H, Krishna C, et al. Is acute reperfusion therapy safe in acute ischemic stroke patients who harbor unruptured intracranial aneurysm? Int J Stroke. 2015;10(Suppl A100):113-118.

3. National Institute of Neurological, Disorders. Stroke rt, P. A. Stroke Study Group. Tissue plasminogen activator for acute ischemic stroke. N Engl J Med. 1995;333(24):1581-1587.

4. Singh K, Mowla A, Mehla S, Ahmed MK, Shirani P, Zimmer WE, Sawyer RN, et al. Safety of intravenous thrombolysis for acute ischemic stroke in patients with preexisting intracranial neoplasms: a case series. Int J Stroke. 2015;10(3):E29-30.

5. Mowla A, Kamal H, Lail NS, Vaughn C, Shirani P, Mehla $\mathrm{S}$, Rajabzadeh-Oghaz H, et al. Intravenous thrombolysis for acute ischemic stroke in patients with thrombocytopenia. J Stroke Cerebrovasc Dis. 2017;26(7):1414-1418.

6. Kamal H, Mowla A, Farooq S, Shirani P. Recurrent ischemic stroke can happen in stroke patients very early after intravenous thrombolysis. J Neurol Sci. 2015;358(12):496-497.

7. AbdelRazek MA, Mowla A, Hojnacki D, Zimmer W, Elsadek R, Abdelhamid N, Elsadek L, et al. Prior asymptomatic parenchymal hemorrhage does not increase the risk for intracranial hemorrhage after intravenous thrombolysis. Cerebrovasc Dis. 2015;40(5-6):201-204.

8. Rajabzadeh-Oghaz H, Varble N, Davies JM, Mowla A, Shakir HJ, Sonig A, Shallwani H, et al. Computer-assist- ed adjuncts for aneurysmal morphologic assessment: toward more precise and accurate approaches. Proc SPIE Int Soc Opt Eng. 2017:10134.

9. Shahjouei S, Tsivgoulis G, Goyal N, Sadighi A, Mowla A, Wang M, Seiffge DJ, et al. Safety of Intravenous Thrombolysis Among Patients Taking Direct Oral Anticoagulants: A Systematic Review and Meta-Analysis. Stroke. 2020;51(2):533-541.

10. Namazi MR, Mowla A. Massive right-sided hemorrhagic pleural effusion due to pancreatitis; a case report. BMC Pulm Med. 2004;4:1.

11. Nogueira RG, Jadhav AP, Haussen DC, Bonafe A, Budzik RF, Bhuva P, Yavagal DR, et al. Thrombectomy 6 to 24 hours after stroke with a mismatch between deficit and infarct. N Engl J Med. 2018;378(1):11-21.

12. Albers GW, Marks MP, Kemp S, Christensen S, Tsai JP, Ortega-Gutierrez S, McTaggart RA, et al. Thrombectomy for stroke at 6 to 16 hours with selection by perfusion imaging. N Engl J Med. 2018;378(8):708-718.

13. Tate WJ, Polding LC, Kemp S, Mlynash M, Heit JJ, Marks MP, Albers GW, et al. Thrombectomy results in reduced hospital stay, more home-time, and more favorable living situations in DEFUSE 3. Stroke. 2019;50(9):2578-2581.

14. Kheiri B, Osman M, Abdalla A, Haykal T, Ahmed S, Hassan M, Bachuwa G, et al. Tenecteplase versus alteplase for management of acute ischemic stroke: a pairwise and network meta-analysis of randomized clinical trials. J Thromb Thrombolysis. 2018;46(4):440-450.

15. Campbell BCV, Mitchell PJ, Churilov L, Yassi N, Kleinig TJ, Dowling RJ, Yan B, et al. Tenecteplase versus alteplase before thrombectomy for ischemic stroke. N Engl J Med. 2018;378(17):1573-1582.

16. Baird AE. Paving the way for improved treatment of acute stroke with tenecteplase. N Engl J Med. 2018;378(17):16351636.

17. Seifi A, Mowla A, Vaziri MM, Talei AR, Namazy MR. Insulin adsorbance to polyvinylchloride (PVC) surfaces of fluid container and infusion-set. Middle East J Anaesthesiol. 2004;17(5):975-981.

18. Parsons M, Spratt N, Bivard A, Campbell B, Chung $\mathrm{K}$, Miteff F, O'Brien B, et al. A randomized trial of tenecteplase versus alteplase for acute ischemic stroke. N Engl J Med. 2012;366(12):1099-1107.

19. Logallo N, Kvistad CE, Nacu A, Naess H, Waje-Andreassen U, Asmuss J, Aamodt AH, et al. The Norwegian tenecteplase stroke trial (NOR-TEST): randomised controlled trial of tenecteplase vs. alteplase in acute ischaemic stroke. BMC Neurol. 2014;14:106.

20. Zitek T, Ataya R, Brea I. Using tenecteplase for acute ischemic stroke: what is the hold up? West J Emerg Med. 2020;21(2):199-202.

21. Burgos AM, Saver JL. Evidence that tenecteplase is noninferior to alteplase for acute ischemic stroke: meta-analysis of 5 randomized trials. Stroke. 2019;50(8):2156-2162.

22. Haley EC, Jr., Thompson JL, Grotta JC, Lyden PD, Hemmen TG, Brown DL, Fanale C, et al. Phase IIB/III trial of tenecteplase in acute ischemic stroke: results of a prematurely terminated randomized clinical trial. Stroke. 2010;41(4):707-711. 